\title{
What leads to high antipsychotic dosing in forensic patients with schizophrenia?
}

\author{
Branimir Margetić, Branka Aukst Margetic, Dragutin Ivanec, \\ and Tija Žarković Palijan
}

Earlier findings suggest that forensic schizophrenia patients are treated with higher doses of antipsychotics. This practice-based specificity is insufficiently studied, and clinicians' motives regarding this practice remain poorly understood. In this editorial, the authors provide their data on treatment of forensic schizophrenia patients and identify characteristics of psychopathology and previous types of behaviors, including suicidal attempts, as potential reasons for the practice. They also emphasize that "these previous acts" often took place years ago, and suggest that current or recent aggression is unlikely the main reason for dosing, but rather the clinicians' intention to maintain "must remain unaggressive" condition. Therefore, the authors suggest new ideas that may contribute to a better understanding of the specific prescribing patterns in the forensic population and hope that these ideas would be implemented in further well-designed prospective studies.

Received 30 August 2016; Accepted 8 September 2016; First published online 19 April 2017

Key words: Forensic psychiatry, antipsychotic drugs, suicide, aggression.

Forensic schizophrenia patients are often treated with higher doses and with more than one antipsychotic. ${ }^{1-5}$ It is assumed that the fundaments of this practice are the lack of responses to the usual doses and the attempts to control violent behavior, though the approach is assumed to be often unnecessary and supporting evidence for its use is weak. ${ }^{1}$

The main topic of "forensic psychopharmacology" is the treatment of aggression. However, the questions of a standardized definition and, consequently, clinical approaches to aggression remain unresolved. Moreover, typical forensic schizophrenia inpatients (at least in Croatia) are too treatment-resistant to have good insight into their condition and the need for continuous treatment, but they take medications and are rarely violent.

The situation is further complicated by the fact that violence may be differently motivated, and that approaches to different types of aggression should differ. $^{6}$ For instance, psychotically motivated offense is probably the main reason for hospitalization of forensic schizophrenia patients, while studies imply that impulsive violence is the main type exhibited by hospitalized patients. ${ }^{6,7}$ Do we then treat current aggression, reasons

\footnotetext{
* Address for correspondence: Dr. Branimir Margetić, Neuropsychiatric Hospital, Jelengradska 1, 44317 Popovača, Croatia.

(Email: branimir.margetic@zg.t-com.hr)
}

for past aggression, or "future danger to self or others"? This unresolved question is what motivates clinicians to prescribe certain dosages.

Thus far, we have reported that forensic patients' histories of mechanical restraint are associated with more intensive positive symptoms and also with the characteristics of personality that may predispose the patients to impulsive reactions. ${ }^{8}$ It is worth noting that the great majority of these patients had been restrained in previous years and none in the 3 months prior to the study. As the use of restraints is dominantly linked with aggression, the findings suggest that the patients' current doses of antipsychotics may be related to aggressive behavior that took place in the past, and which was not only a consequence of symptoms but also associated with the characteristics of their personality. ${ }^{8}$ Moreover, the findings are in accordance with some previous findings that indicated that violence is generally more common in treatment-resistant psychotic patients. ${ }^{9-11}$ It is logical to expect that those patients "need" higher doses.

However, we had conducted a larger study, and one of the aims was to assess the relationships between treatment strategies and different behaviors in this population. There are no reports related to a possible association of the doses with the seriousness of offense or suicidality that occurs more frequently in aggressive schizophrenia patients. ${ }^{12-14}$ Thus, it would be valuable 
to present data related to the issues, while the more detailed descriptions of the selection of the subjects and the instruments used are present elsewhere. ${ }^{8,15}$

The sample in our study comprised 54 forensic male patients with schizophrenia or schizoaffective disorder, but without comorbid antisocial personality disorder or substance dependence.

The mean age of participants was $44.7( \pm 8.39)$ years. The duration of institutionalization was $6.6( \pm 5.08)$ years. The predominant diagnostic subgroup was paranoid schizophrenia ( $\mathrm{N}=42 ; 77.8 \%)$. In the "homicidal" group, 4 of the 22 patients attempted homicide, while others committed homicide. In the "other offenses group" ( $\mathrm{N}=32 ; 59.3 \%$ of all patients), the predominant act was assault on others $(\mathrm{N}=27 ; 84.4 \%$ of the group). Fifteen patients attempted suicide. All attempts had taken place a number of years before the study, and all but 2 were committed before hospitalization. The Positive and Negative Syndrome Scale (PANSS) score was 85.4 $( \pm 15.66)$; the positive symptoms subscale score was 19.4 $( \pm 4.52)$, the negative symptoms subscale score was 23.2 $( \pm 5.23)$, and the general psychopathology symptoms subscale score was $42.7( \pm 8.61)$. The mean chlorpromazine equivalent dose, calculated according to recommendations, ${ }^{16}$ was $913.3( \pm 489.04) \quad$ CPZeq/day. The recommended dosage is usually below $600 \mathrm{CZPeq} /$ day, and the maximal approved dosage in many countries is $1000 \mathrm{CZPeq} /$ day. ${ }^{17}$ In this study, 15 patients were given the dose of up to $600 \mathrm{CZPeq} /$ day, and 15 were given 1000 CZPeq/day or higher. Accordingly, there is no doubt that the majority of patients were treated with higher than usual doses, and a substantial proportion of them with even higher than maximum doses. Consequently, we conducted a more detailed analysis of the motivation for prescribing these higher doses.

The doses correlated with PANSS scores $(\mathrm{r}=355$; $\mathrm{p}=0.008)$, positive symptoms $(\mathrm{r}=0.479, \mathrm{p}<0.001)$, and symptoms of general psychopathology $(\mathrm{r}=0.324$, $\mathrm{p}=0.017)$, but not with negative symptoms $(\mathrm{r}=0.118$, $\mathrm{p}=0.397)$. All items from the positive subscale, except "hostility" (P7; r = -0.027, p = 0.846), correlated with the antipsychotic dosage. The most prominent correlations between positive symptoms items and dosage were for "delusions" (P1; r = 0.455, $\mathrm{p}=0.001)$ and "conceptual disorganization" (P2; $\mathrm{r}=0.403, \mathrm{p}=0.003)$. It is worth noting that the mean "hostility" item score was $1.78( \pm 0.984)$. There was no significant correlation with any item from the negative subscale. A number of general symptoms subscale items showed significant correlation, which was highest with "unusual thought content" (G9; $\mathrm{r}=0.429, \mathrm{p}=0,001)$. However, significant correlations were not found with "guilt feelings" (G3; $\mathrm{r}=0.169$, $\mathrm{p}=0.222$ ) or "depression" (G6; $\mathrm{r}=0.155, \mathrm{p}=0.263$ ).

This cross-sectional study provides only more or less speculative explanations. It has been suggested that forensic patients are treated with higher doses due to violence. Nevertheless, all patients who took part in the study were on a stable medication regime, and their mean score in the "hostility" item was rather low. Thus, one may suppose that the "hostility" item is the target, and that the dosages should increase until side effects or the scores are as low as they are in this study. Here, we emphasize that the aim of forensic treatment is not only to decrease the intensity of schizophrenia symptoms, but also to decrease the risk of violent reoffending and, ultimately, to protect society.

Another reason that higher doses are used is not because the patients are violent, but rather because they "must remain unaggressive." Here, a number of unresolved questions appear, and one seems to be especially intriguing. If schizophrenia per se does not explain the development of violence, and if the target of treatment with antipsychotics is aggression, does it mean that the dose for treatment of the "must remain unaggressive" condition should be the same as for schizophrenia?

On the other hand, psychotically motivated violent offenses are characteristically dominantly motivated by positive symptoms, among them delusions. The clinician's intention to deal with these symptoms in patients with long-lasting mean PANSS scores above 80 seems to be an acceptable explanation. Accordingly, if the positive symptoms are intensive, and/or refractory to the treatment, the doses are high because of the clinician's fear or insecurity. This is in accordance with the findings by Fazel et $a l,{ }^{18}$ who found that in differently diagnosed persons with criminal convictions, the rate of violence reduction was stronger if the prescribed doses of antipsychotics were higher.

Probably the most interesting finding is that there was no significant difference between the doses of patients who had committed or attempted homicide and those who had committed other offenses, but there was a difference between those who had and those who had not attempted suicide (Table 1). The effect size for the analysis was large (Cohen's $d=0.96$ ). As shown in the table, there were no significant differences in psychopathology scores regardless of whether the patients were dichotomized according to a type of offense or previous suicide attempt.

In fact, this could be the first description of a possible association between doses of antipsychotics and previous suicidal attempts in forensic schizophrenia patients. Reports with some similarities exist, but the most recent review regarding the association between antipsychotic dosage and suicidal behavior in schizophrenia showed mixed results and provided no clear conclusion. ${ }^{19}$ Furthermore, previous studies used different methodologies, and their comparability is questionable.

For example, Taiminen and $\mathrm{Kujari}^{20}$ found lower neuroleptic doses in suicidal patients, but suggested that 
TABLE 1. Differences between groups regarding age, antipsychotic dosing, and severity of psychopathology tested with t-tests

\begin{tabular}{|c|c|c|c|c|c|c|c|c|}
\hline & $\begin{array}{l}\text { Homicide and attempted homicide } \\
\qquad \mathrm{N}=22 \\
\text { Mean (SD) }\end{array}$ & $\begin{array}{l}\text { Other offenses } \\
\qquad \mathrm{N}=32 \\
\text { Mean (SD) }\end{array}$ & $t$ & $\mathrm{p}$ & $\begin{array}{l}\text { Attempted suicide } \\
\qquad \begin{array}{l}\mathrm{N}=15 \\
\text { Mean (SD) }\end{array}\end{array}$ & $\begin{array}{l}\text { Without attempted suicide } \\
\qquad \begin{array}{l}\mathrm{N}=39 \\
\text { Mean (SD) }\end{array}\end{array}$ & $t$ & $p$ \\
\hline Age & 44.5 (8.49) & $45.0(8.46)$ & -.195 & .846 & $46.3(7.55)$ & $44.2(8.72)$ & .831 & .410 \\
\hline Dose & $931.9(542.73)$ & $900.5(457.09)$ & .229 & .820 & $1228.8(585.03)$ & 792.0 (391.24) & 3.183 & .002 \\
\hline PANSS & $81.3(16.04)$ & 88.1 (15.03) & -1.591 & .118 & $86.7(20.29)$ & 84.8 (13.77) & .379 & .706 \\
\hline Pos & $18.8(4.37)$ & 19.9 (4.64) & -.767 & .447 & 20.4 (5.11) & $19.0(4.27)$ & 1.090 & .281 \\
\hline $\mathrm{Neg}$ & $22.1(5.52)$ & $24.0(4.97)$ & -1.272 & .209 & $22.5(4.83)$ & $23.5(5.41)$ & -.654 & .516 \\
\hline Gen & $40.4(8.13)$ & $44.4(8.68)$ & -1.712 & .093 & 43.7 (11.93) & $42.4(7.10)$ & .522 & .604 \\
\hline
\end{tabular}

Dose: chlorpromazine equivalent daily dose (mg); PANSS: Positive and Negative Syndrome Scale scores; Pos: positive symptoms subscale scores; Neg: negative symptoms subscale scores; Gen: general psychopathology symptoms subscale scores.

results were probably a consequence of the differences in the symptom profile. Hettige et $a l^{21}$ did not confirm the hypothesis that the doses are associated with the history of suicide attempts in patients with schizophrenia. In a recent article related to the topic, Reutfors $e t a l^{22}$ reported a lower suicide risk in schizophrenia patients with a history of extrapyramidal symptoms, and suggested that this "could reflect higher antipsychotic adherence, exposure to higher dosage, or polypharmacy among these patients (p. 341)."

However, the main differences between this and other studies are that the subjects in this study were only male patients with a history of serious, mostly violent, offenses. As mentioned above, aggressive schizophrenia patients are at increased risk for suicide. ${ }^{12-14}$

Taken together, our findings suggest that forensic patients are not treated with higher doses because they are currently violent or have been violent in recent months. We would rather assume that prescribing patterns are influenced by current psychopathology and also by the patients' previous actions, which in the majority of subjects in this study took place years ago.

Nevertheless, without prospective studies that would follow a larger number of variables including psychopathology, and specific and important types of behavior and personality (which are interconnected with both psychopathology and behavior), we do not understand the clinicians' motives for differences in prescribing patterns of antipsychotics in this population.

\section{Disclosures}

The authors do not have anything to disclose.

\section{REFERENCES:}

1. Morrissette DA, Stahl SM. Treating the violent patient with psychosis or impulsivity utilizing antipsychotic polypharmacy and high-dose monotherapy. CNS Spectr. 2014; 19(5): 439-448.
2. Barnes TR, Paton C. Antipsychotic polypharmacy in schizophrenia: benefits and risks. CNS Drugs. 2011; 25(5): 383-399.

3. Stahl SM, Morrissette DA, Cummings M, et al. California State Hospital Violence Assessment and Treatment (Cal-VAT) guideline. CNS Spectr. 2014; 19(5): 449-465.

4. Stone-Brown K, Naji M, Francioni A, et al. Psychotropic prescribing in seriously violent men with schizophrenia or personality disorder in a UK high security hospital. CNS Spectr. 2016; 21(1): 60-69.

5. Connolly A, Taylor D. Factors associated with non evidence-based prescribing of antipsychotics. Ther Adv Psychopharmacol. 2014; 4(6): 247-256.

6. Stahl SM. Deconstructing violence as a medical syndrome: mapping psychotic, impulsive, and predatory subtypes to malfunctioning brain circuits. CNS Spectr. 2014; 19(5): 357-365.

7. Quanbeck C. Forensic psychiatric aspects of inpatient violence. Psychiatr Clin North Am. 2006; 29(3): 743-760.

8. Margetić B, Aukst Margetić B, Ivanec D. Temperament and character in patients with schizophrenia with a history of restraint. The Journal of Forensic Psychiatry \& Psychology. 2013; 24(5): 621-633.

9. Ehmann TS, Smith GN, Yamamoto A, et al. Violence in treatment resistant psychotic inpatients. J Nerv Ment Dis. 2001; 189(10): 716-721.

10. Nolan KA, Volavka J, Czobor P, et al. Aggression and psychopathology in treatment-resistant inpatients with schizophrenia and schizoaffective disorder. J Psychiatr Res. 2005; 39(1): 109-115.

11. Conley RR, Buchanan RW. Evaluation of treatment-resistant schizophrenia. Schizophr Bull. 1997; 23(4): 663-674.

12. Apter A, Kotler M, Sevy S, et al. Correlates of risk of suicide in violent and nonviolent psychiatric patients. Am J Psychiatry. 1991; 148(7): 883-887.

13. Montross LP, Zisook S, Kasckow J. Suicide among patients with schizophrenia: a consideration of risk and protective factors. Ann Clin Psychiatry. 2005; 17(3): 173-182.

14. McGirr A, Turecki G. What is specific to suicide in schizophrenia disorder? Demographic, clinical and behavioural dimensions. Schizophr Res. 2008; 98(1-3): 217-224.

15. Margetić B, Aukst Margetić B, Ivanec D. Opinions of forensic schizophrenia patients on the use of restraints: controversial legislative issues. Psychiatr Q. 2014; 85(4): 405-416.

16. Gardner DM, Murphy AL, O'Donnell H, et al. International consensus study of antipsychotic dosing. Am J Psychiatry. 2010; 167(6): 686-693.

17. Hasan A, Falkai P, Wobrock T, et al. WFSBP Task force on Treatment Guidelines for Schizophrenia. World Federation of Societies of Biological Psychiatry (WFSBP) guidelines for biological 
treatment of schizophrenia, part 2: update 2012 on the long-term treatment of schizophrenia and management of antipsychotic-induced side effects. World J Biol Psychiatry. 2013; 14(1): 2-44.

18. Fazel S, Zetterqvist J, Larsson H, et al. Antipsychotics, mood stabilisers, and risk of violent crime. Lancet. 2014; 384(9949). 1206-1214.

19. Kasckow J, Felmet K, Zisook S. Managing suicide risk in patients with schizophrenia. CNS Drugs. 2011; 25(2): 129-143.
20. Taiminen TJ, Kujari H. Antipsychotic medication and suicide risk among schizophrenic and paranoid inpatients. A controlled retrospective study. Acta Psychiatr Scand. 1994; 90(4): 247-251.

21. Hettige NC, Kennedy JL, De Luca V. Does a history of suicide attempt predict higher antipsychotic dosage in schizophrenia? Psychopharmacology (Berl). 2014; 231(12): 2507-2513.

22. Reutfors J, Clapham E, Bahmanyar S, et al. Suicide risk and antipsychotic side effects in schizophrenia: nested casecontrol study. Hum Psychopharmacol. 2016; 31(4): 341-345. 